\title{
First experiences in non-intubated, video-assisted thoracoscopic surgery: a single-centre study
}

\author{
Tayfun Kermenli ${ }^{1}$, Cebrail Azar ${ }^{2}$, Zafer Gundogdu ${ }^{3}$ \\ ${ }^{1}$ Department of Thoracic Surgery, Istanbul Aydın University, Istanbul, Turkey \\ ${ }^{2}$ Department of Chest Diseases, Medicalpark Elazığ Hospital, Istinye University, Istanbul, Turkey \\ ${ }^{3}$ Department of Aesthesiology and Reanimation, Medicalpark Elazığ Hospital, Istinye University, Istanbul, Turkey
}

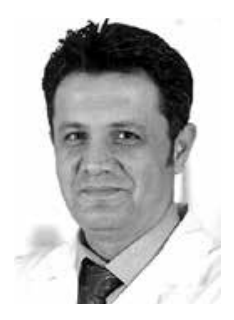

Kardiochir Torakochir Pol 2021; 18 (1): 15-22

\begin{abstract}
Introduction: Video-assisted thoracoscopic surgery (VATS) with non-intubated technique is safely performed under spontaneous breathing and sedation. With this surgery, many complex thoracic surgical interventions can be successfully applied.

Aim: We shared the results of our patients who underwent mediastinal biopsy, pleural biopsy, lung wedge resection, pneumothorax surgery, and pleural delocculation with non-intubated VATS.

Material and methods: Patients who underwent surgery with non-intubated VATS between March 2015 and May 2020 in our clinic were included in the study. The patients were evaluated in terms of many factors such as age, gender, applied surgical intervention, diagnosis, side of surgery, duration of surgery, and time of hospital stay, and the results were recorded retrospectively. Results: Twenty of the patients were male and 12 were female. Regarding comorbid diseases in our patient group, 13 had extrathoracic malignancy, 7 had hypertension, 6 had heart disease, 5 had chronic obstructive pulmonary disease and asthma, and 4 had diabetes mellitus. Pleural drainage and biopsy were performed in 10 patients and wedge resection in 8 patients. Bullectomy and apical pleural abrasion were performed in 6 patients, mediastinal mass biopsy was performed in 4 patients, and delocculation was performed in 4 patients due to empyema.

Conclusions: The non-intubated VATS approach can be safely applied in procedures such as lung resections, pleural or mediastinal interventions, and pneumothorax surgery. With this technique, the absence of intubation and mechanical ventilation facilitates the return to normal respiratory physiology, and we think that the recovery time of the patient, the duration of hospital stay, and treatment costs are reduced.
\end{abstract}

Key words: non-intubated, video-assisted thoracoscopic surgery, local anaesthesia, sedation.

\section{Introduction}

Single lung ventilation under general anaesthesia is the traditional anaesthesia technique used for chest surgery operations. This method creates a safe and optimal workspace for manipulations in thoracotomy and video-assisted thoracoscopic surgery (VATS) during surgery. On the other hand, with the help of video-assisted thoracoscopy in thoracic surgery, uniportal or biportal incisions have started to be used, and a tendency towards using a less invasive technique has occurred [1]. This situation also led to the development and change of anaesthesia techniques [2]. While single lung ventilation was performed with options such as bronchial blocker or double-lumen intubation, case series with increasing rates of non-intubated surgery have been reported in the literature in recent years [3]. In some studies, it is thought that general anaesthesia and deep sedation applied in thoracic surgery operations may cause more cognitive dysfunction than regional anaesthesia. On the other hand, it has been reported that single lung ventilation can increase atelectasis by creating perfusion inbalance [4]. As a result, in the postoperative period, spontaneous breathing was preferred to mechanical ventilation, for the respiratory parameters to return to normal more rapidly.

The most important issue for non-intubated VATS (NIVATS) is to provide a spontaneous pneumothorax as the surgeon enters the thorax. In this way, perfect lung isolation can be achieved without the need for positive pressure ventilation in the opposite lung [5]. When supported with local anaesthesia, it is an extremely comfortable anaesthesia technique for the patient. In many studies, the hospital stay is shortened with this technique, postoperative recovery speeds up and general anaesthesia side effects are not seen, and hospital costs are also decreasing [6]. It has been

Address for correspondence: Tayfun Kermenli MD, Department of Thoracic Surgery, Istanbul Aydın University, Istanbul, Turkey, phone: +90 4242348000, e-mail: tayfunkermenli@gmail.com

Received: 22.12.2020, accepted: 15.02.2021. 
shown that many video thoracoscopic surgeries, including anatomical lung resections, can be performed safely, with many reported patient series [7].

For non-intubated video-assisted thoracoscopic surgery, it is recommended that appropriate patients be selected at the initial stage, especially before the surgical and anaesthesia team gains experience [8]. It is reported that these cases should include pleural biopsy, peripheral lung

Table I. Inclusion and exclusion criteria of patients

\begin{tabular}{|c|c|}
\hline Inclusion criteria & Exclusion criteria \\
\hline $\begin{array}{l}\text { 1. The duration of surgery is } \\
\text { less than } 2 \text { hours } \\
\text { 2. Patients who are scheduled } \\
\text { for pleural biopsy, lung } \\
\text { biopsy, pulmonary wedge } \\
\text { resection, pneumothorax } \\
\text { surgery, or mediastinal } \\
\text { tumour biopsy } \\
\text { 3. No major bleeding risk } \\
\text { 4. Non-obese patients BMI } \\
<30 \mathrm{~kg} / \mathrm{m}^{2} \\
\text { 5. Patients without a difficult } \\
\text { intubation history } \\
\text { 6. No respiratory distress } \\
\text { 7. No serious arrhythmia or } \\
\text { cardiac disease }\end{array}$ & $\begin{array}{l}\text { 1. The history of having } \\
\text { thoracic surgery on the same } \\
\text { hemithorax } \\
\text { 2. Patients with complex surgery } \\
\text { planned } \\
\text { 3. People with known allergies to } \\
\text { local anaesthetics } \\
\text { 4. Patients with abnormalities in } \\
\text { bleeding parameters } \\
\text { 5. Obese patients } \mathrm{BMI}>30 \mathrm{~kg} / \mathrm{m}^{2} \\
\text { 6. Difficult intubation history and } \\
\text { short neck } \\
\text { 7. } \mathrm{Hypoxaemia}\left(\mathrm{PaO}_{2}<60 \mathrm{~mm} \mathrm{Hg}\right) \\
\text { or preoperative hypercapnia } \\
\left(\mathrm{PaCO}_{2}>50 \mathrm{~mm} \mathrm{Hg}\right)\end{array}$ \\
\hline
\end{tabular}

Table II. Clinical characteristics of patients

\begin{tabular}{|c|c|c|}
\hline Parameter & $\begin{array}{l}\text { Non-intubated } \\
\text { group }(n=32)\end{array}$ & $\%$ \\
\hline Age & $52.2 \pm 17.8(15-76)$ & \\
\hline \multicolumn{3}{|l|}{ Gender: } \\
\hline Male & 20 & 62.5 \\
\hline Female & 12 & 37.5 \\
\hline \multicolumn{3}{|l|}{ Comorbidity: } \\
\hline Extrathoracic malignancy & 13 & 40.6 \\
\hline Hypertension & 7 & 21.9 \\
\hline Diabetes mellitus & 4 & 12.5 \\
\hline Cardiac diseases & 6 & 18.8 \\
\hline COPD, asthma & 5 & 15.6 \\
\hline \multicolumn{3}{|l|}{ ASA physical status class: } \\
\hline I & 8 & 25 \\
\hline ॥ & 12 & 37.5 \\
\hline III & 7 & 21.9 \\
\hline IV & 5 & 15.6 \\
\hline \multicolumn{3}{|l|}{ Surgical procedure: } \\
\hline Diagnostic & 18 & 56.2 \\
\hline Therapeutic & 14 & 43.8 \\
\hline \multicolumn{3}{|l|}{ Lesion localisation: } \\
\hline Left & 10 & 31.2 \\
\hline Right & 22 & 68.8 \\
\hline
\end{tabular}

nodule, or mediastinal mass biopsy [9]. In line with this information, we started our first experiences by selecting patients with suitable NI-VATS.

\section{Aim}

In this article, we shared the results of our patients who underwent mediastinal biopsy, pleural biopsy, lung wedge resection, and pleural delocculation with NI-VATS.

\section{Material and methods}

Patients who underwent surgery with non-intubated VATS between March 2015 and May 2020 in our clinic were included in the study. Written informed consent was obtained from each patient. The study was conducted in accordance with the principles of the Declaration of Helsinki. In the first period, from the patients who were scheduled to undergo a pleural biopsy, patients with a high general anaesthesia risk and a short estimated duration of surgery were NI-VATS technique was preferred. However, following the increase in the experience of the anaesthesia and surgical team, patients in whom ASA I-IV, pleural biopsy, peripheral nodule, lung biopsy, or wedge resection were planned, mediastinal mass biopsy, pneumothorax surgery, and empyema delocculation were also included. The patients were informed before the operation, and this technique was applied to the patients who preferred NI-VATS. Patient selection and exclusion criteria for non-intubated anaesthesia are given in Table I.

\section{Sedation and local anaesthesia technique}

The patients were evaluated in detail by the anaesthesia team before, and their preparations were made as they would be for routinely applied for general anaesthesia. In case of intubation requirement, they were informed about what to do, and an anaesthesia informed consent form was obtained from all patients. The patients who were taken to the operating room were primarily monitored; electrocardiogram, pulse rate, blood pressure, oxygen saturation (SpO2), and respiratory rate were followed. During the operation, oxygen saturation was monitored by pulse oximeter, and high-flow oxygen support was given from the nasal cannula to maintain the oxygen saturation above $95 \%$. Following the opening of the patient's vascular access, midazolam $0.05 \mathrm{mg} / \mathrm{kg}$ (Dormicum $15 \mathrm{mg} / 3 \mathrm{ml}$ ) was injected intravenously for sedation. Fentanyl $(0.05 \% \mathrm{mg} / \mathrm{ml})$ $0.5 \mathrm{mg} / \mathrm{kg}$ bolus and $6 \mathrm{mg} / \mathrm{kg} / \mathrm{h}$ infusion or propofol (Propofol $1 \%, 200 \mathrm{mg} / 20 \mathrm{ml}) 0.5 \mathrm{mg} / \mathrm{kg}$ bolus and $3 \mathrm{mg} / \mathrm{kg} / \mathrm{h}$ infusion were started. As a local anaesthetic, $2.5 \mathrm{ml}$ of $0.5 \%$ bupivacaine (Buvasin 0.5\%, $20 \mathrm{ml}$ ) was applied to the incision site. In the patients who underwent surgery due to spontaneous pneumothorax and pleural abrasion, local anaesthesia was provided to the parietal pleura by giving bupivacaine into the thorax during the perioperative period. Vagal nerve blockade was performed with $0.5 \%$ bupivacaine to prevent the cough reflex in patients for whom it was deemed necessary. 


\section{Surgical technique}

The right or left lateral decubitus position was given to the patients according to the planned surgical procedure. For the mediastinal mass biopsy, a $30^{\circ}$ supine position with a back support pad was given. In each patient, a single $2-\mathrm{cm}$ incision was opened as standard, and exploration was performed with a $5-\mathrm{mm} 30^{\circ}$ thoracoscope camera (Karl Storz endoscope; Karl Storz, Tuttlingen, Germany). When necessary, a second incision was opened and the operation was completed biportally. Endo grasper, endo cautery, endo dissector, and surgical energy devices were used as surgical instruments. At the end of the operation, Hemovac drainage or thorax drains were placed in the thorax according to the surgeon's preference.

\section{Statistical analysis}

All data on clinical results before and after surgery were collected and analysed retrospectively. The findings from the patients were analysed with SPSS software (SPSS Inc., Chicago, IL, USA) using a mean and standard devia- tion (SD) with a 95\% confidence interval (CI). Frequency and percentage were calculated for gender, comorbidity, ASA physical condition class, surgical procedure, and lesion localization. Findings such as anaesthesia induction time, operation time, drain removal time, and hospital stay were recorded.

\section{Results}

Between March 2015 and May 20, 32 patients underwent VATS under sedation and local anaesthesia without intubation. All patients were evaluated with appropriate imaging methods such as thorax computed tomography (CT) or positron emission tomography (PET) in the preoperative period. The mean age of the patients was $52.2 \pm 17.8$ years (15-76). Twenty (62.5\%) of the patients were male, and 12 (37.5\%) were female. As comorbid disease in our patient group, $13(40.6 \%)$ had extra-thoracic malignancy, hypertension 7 (21.9\%), heart disease 6 (18.8\%), COPD and asthma $5(15.6 \%)$, and $4(12.5 \%)$ patients had diabetes mellitus. According to the ASA (American Society of Anesthesiologists)
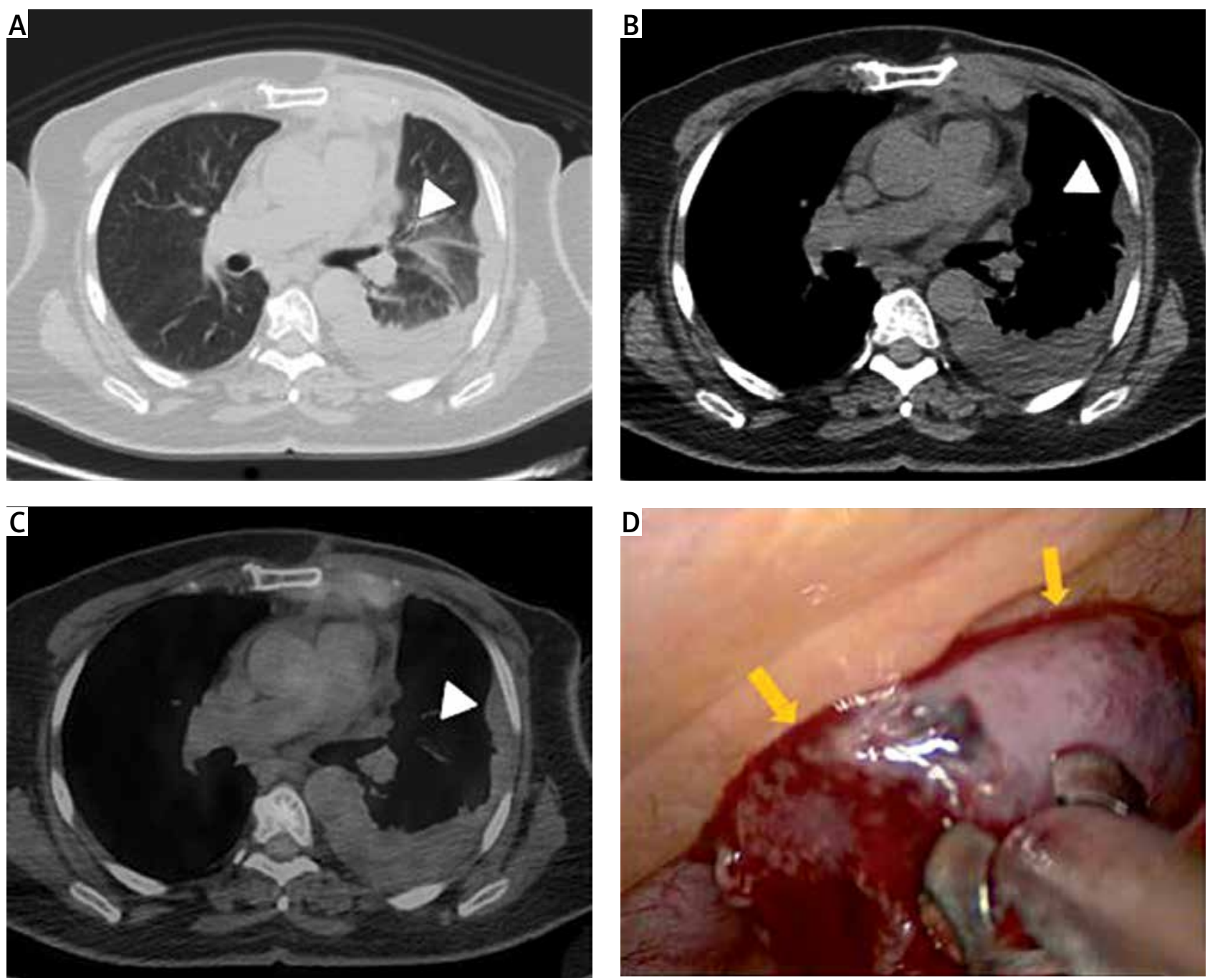

Figure 1. Pleural metastasis of breast ca. A, B - Thorax CT images (arrowhead), C - PET-CT images, D - Intraoperative view of the tumor (yellow arrow) 
score in the preoperative evaluation, there were ASA-I: 8, ASA-II: 12, ASA-III: 7, and ASA-IV: 5 patients. Video thoracoscopy procedure was performed for diagnostic purposes in 18 (56.2\%) cases and for therapeutic purposes in 14 (43.8\%) cases. Demographic and preoperative findings of the patients are given in Table II.

Patients were placed on the operating table according to the area to be treated. Mediastinal mass biopsy was performed in a $30^{\circ}$ supine position by placing a lower back elevation, and the right or left lateral decubitus position was preferred for other VATS procedures. Twenty-two (68.8\%) patients underwent right hemithorax, and the left side was used in $10(31.2 \%)$ patients. Pleural drainage and biopsy were performed in 10 (31.2\%) of 32 patients (Figure 1), and wedge resection was performed in 8 patients. Three of these were procedures performed for interstitial lung disease biopsy (Figure 2), and the remaining 5 patients were operated on for metastasectomy due to lung metastasis of extrathoracic malignancy. Bullectomy and apical pleural abrasion were performed in 6 of our patients due to spontaneous pneumothorax (Figure 3). In these patients, local anaesthesia was achieved by applying $50 \mathrm{ml}$ isotonic solution, $10 \mathrm{ml}$ bupivacaine to the thoracic cavity to prevent
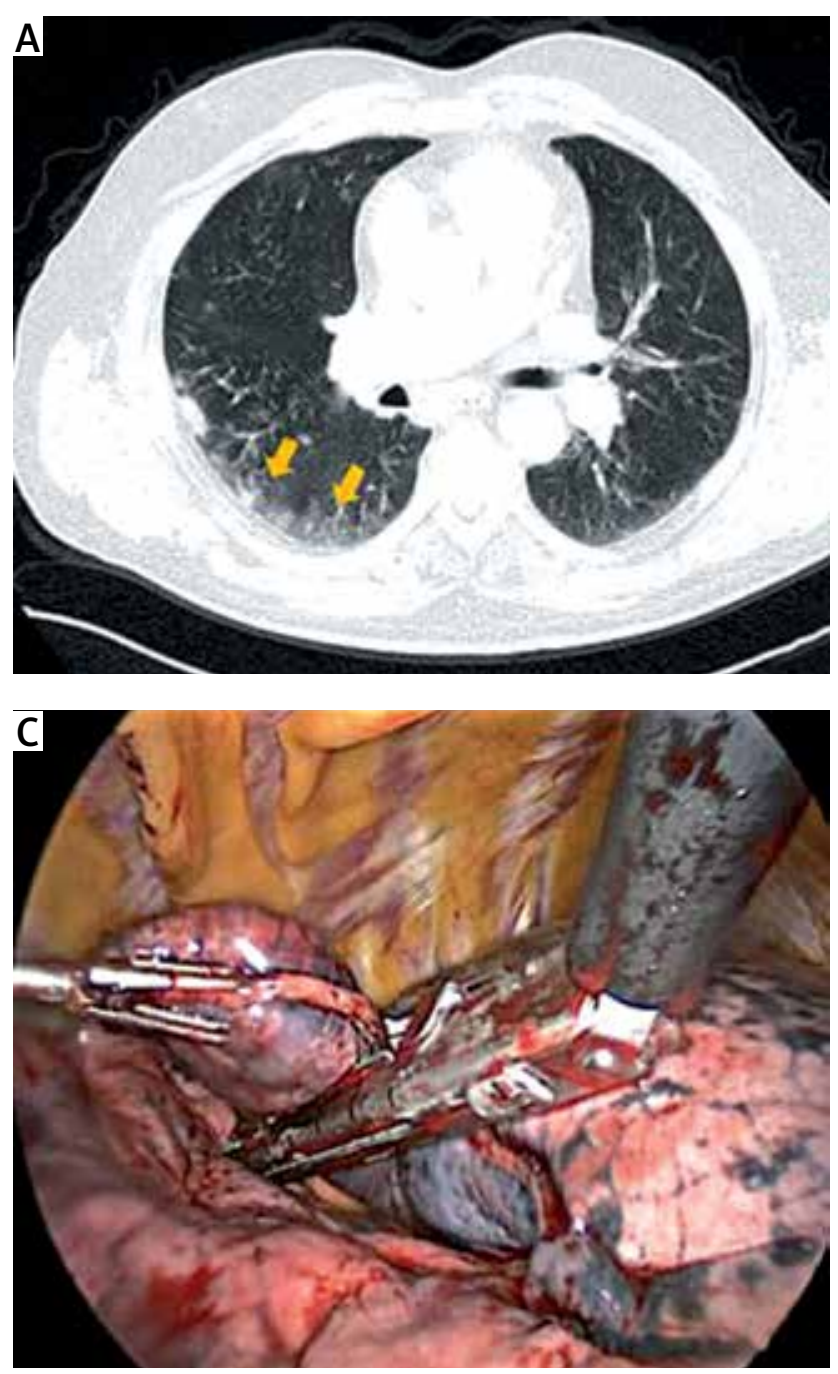

pleural pain. The mediastinal mass biopsy was performed in 4 (12.5\%) patients (Figure 4), and delocculation was performed in $4(12.5 \%)$ patients due to empyema (Table III). Hemovac drains were used in 16 (50\%), $20 \mathrm{Fr}$ in 10 (31.2\%), and $28 \mathrm{Fr}$ thorax drains in 6 (18.8\%) (Table IV).

If the operation time is prolonged, or if the sedative effect disappears in the patient, additional doses of medication are given to continue the sedation. Both the paincontrolling feature and the sedative effect of fentanyl were used. The mean anaesthesia induction time was $21 \pm 3.6$ (15-30) minutes. After an appropriate position was given to the patient, local anaesthesia was applied with bupivacaine to the incision areas planned according to thorax CT before the operation. According to the surgical plan, 1 or 2 ports were opened. While the number of cases we operated uniportally was 13 (40.6\%), the number of biportal cases was 19 (59.4\%). During the operation, our average blood loss was measured as $16.4 \pm 0.64$ (5-50) $\mathrm{ml}$ (Table IV). Following sedation, patients were followed up with spontaneous breathing, and high current oxygen support was provided so that the oxygen saturation did not fall below 95\%. There were no patients in our patients who had to undergo intubation or who underwent thoracotomy in the perioperative period.

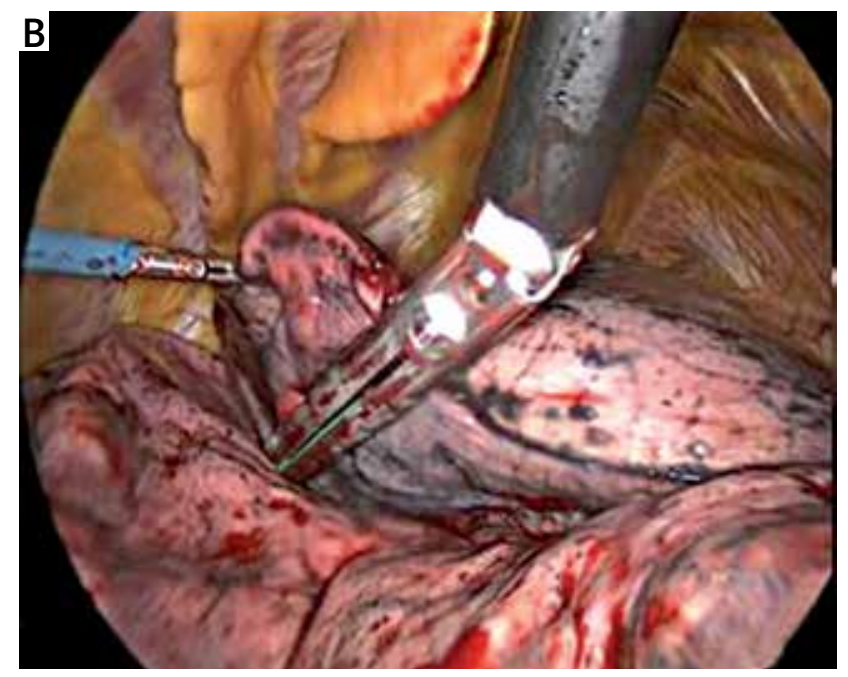

Figure 2. A - Interstitial lung involvement in the posterior segment of the right lung (yellow arrow), B, C - Intraoperative view of wedge resection 

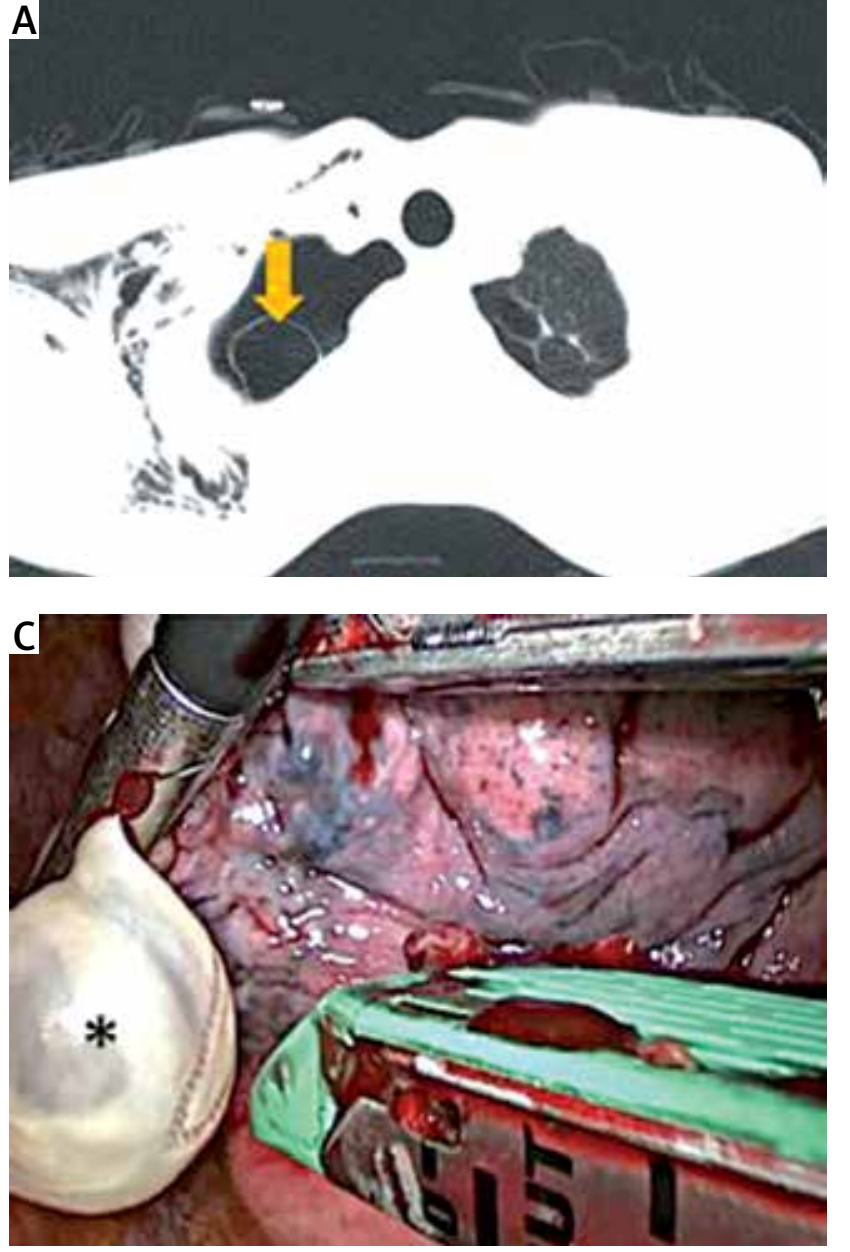
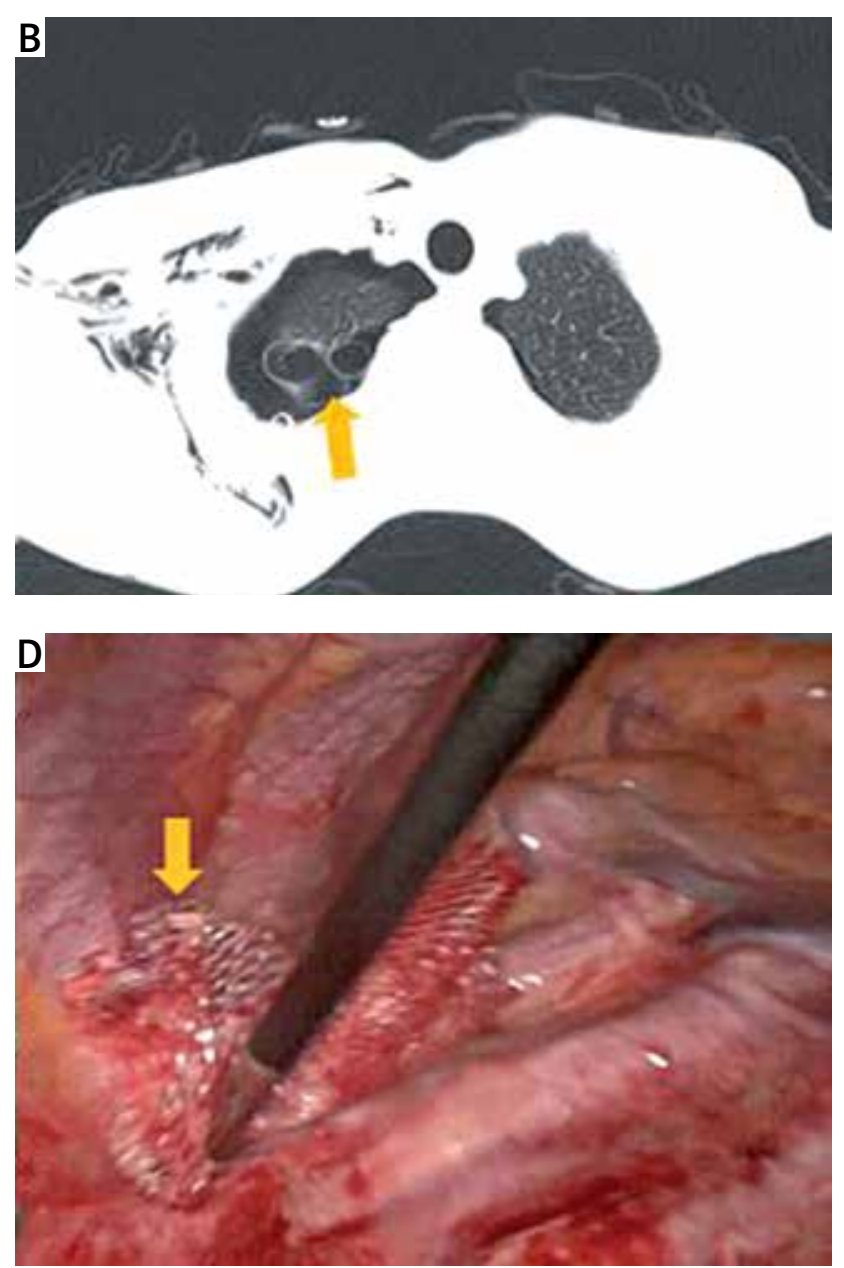

Figure 3. A, B - Images of apical bullae of the right lung (yellow arrow). C - Intraoperative view of the bullectomy, bullae (asterisk). D - Apical pleural abrasion with prolene mesh (yellow arrow)

In the postoperative period, only 1 of our patients complained of nausea that would require medical treatment as a side effect after anaesthesia in their clinical follow-up. The pain scores of the patients at the postoperative $24^{\text {th }}$ hour were measured with the Visual Analogue Scale (VAS) pain scoring technique. The mean VAS score in the first 24 hours postoperatively was found to be $2 \pm 0.6$ (1-3). As a complication, prolonged air leakage was observed in 1 patient and cardiac arrhythmia was observed in 1 patient. The mean drain removal time was $1.75 \pm 0.80$ (1-4) days, and the hospital discharge time was found to be $2.3 \pm 1.25$ (1-5) days. There was no mortality among our patients in the first postoperative month. Perioperative and postoperative information of our patients are given in Table IV.

\section{Discussion}

The most important stress source encountered by patients for thoracoscopic surgery is that of providing single lung ventilation with general anaesthesia and doublelumen intubation. In terms of the postoperative period, paralysis caused by general anaesthesia affects the operation of the diaphragmatic muscle and normal respiratory physiology, thus increasing the risk of atelectasis [10]. Also, mechanical ventilation has some potential side effects such as pressure-related injury, lung overstretching, and the release of various pro-inflammatory mediators [11]. These reasons have enabled thoracic surgeons to prefer NI-VATS at increasing rates. On the other hand, it is aimed to avoid postoperative side effects and complications related to general anaesthesia. With this anaesthesia technique, there will be no serious change in normal respiratory physiology, and patient recovery is faster [12].

In our clinic, we preferred non-intubated VATS in our patients who were at high risk in terms of general anaesthesia, but who required surgery for diagnosis, in our ASA-III and IV patients. With the increase of our experience, we have started to use especially in peripheral lung nodules, interstitial lung disease, lung biopsy, mediastinal mass biopsies, empyema delocculation, and pneumothorax treatment. Up to this stage, we have not only performed anatomical lung resection. When choosing our first patients, cases such as pleural biopsy with a short surgery duration and low complication risk were preferred. In our case series, patients with ASA III-IV and high comorbidity were at the forefront, and as our experience increased, the proportion of our ASA I-II patients also increased. 

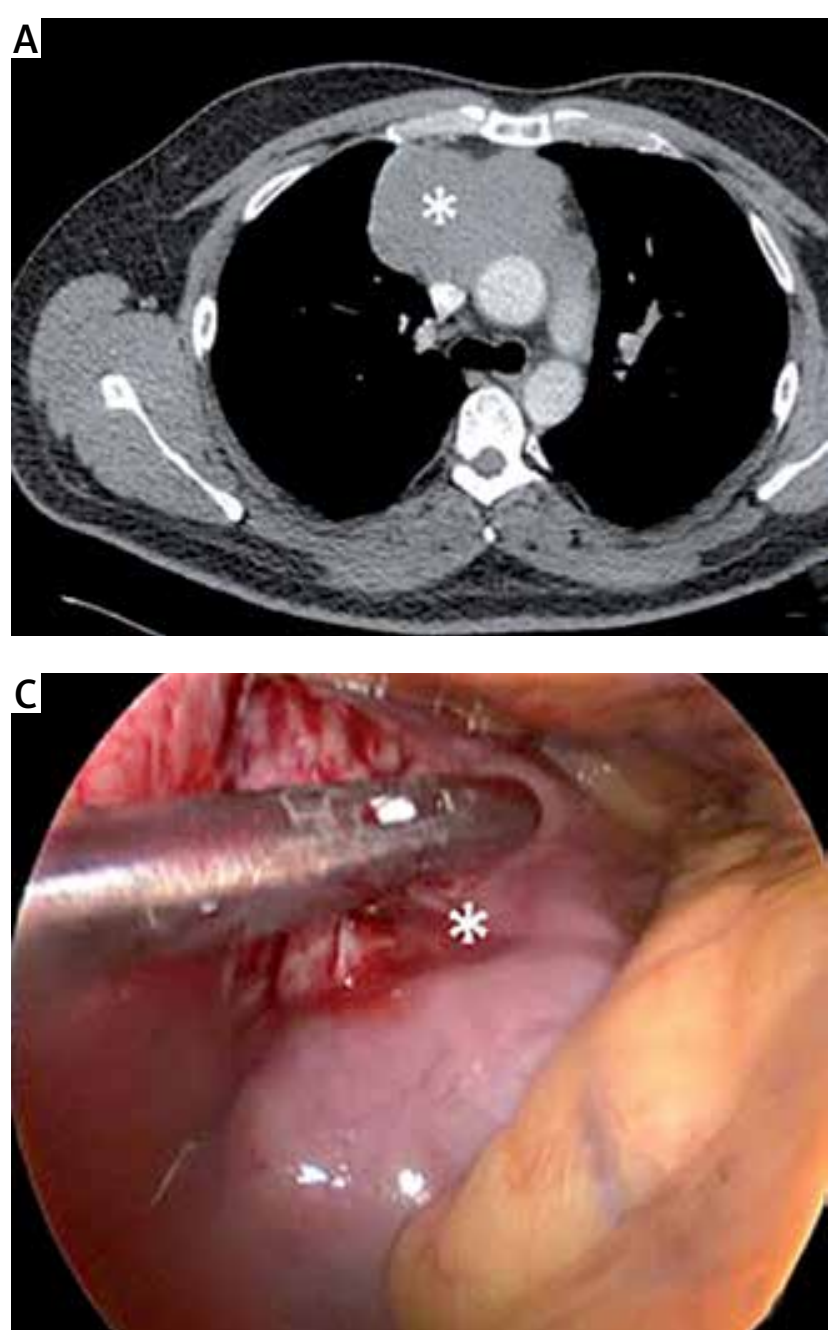

We see that our patient group consists of heterogeneous patients, and we have not performed complex lung surgery yet. However, we can see that complex lung surgeries can be performed safely, with case series reported in the literature. Surgical procedures such as sleeve lung resections were reported after single-port thoracoscopic lobectomy in a non-intubated patient reported by Gonzales [13]. After Shao et al. [14] reported that they successfully performed sleeve resection in a non-intubated patient, there was an increase in the case series in which non-intubated lung resections were performed recently. In these series, we see that epidural anaesthesia is used in addition to sedation and local anaesthesia [14]. In our series, there were no patients who underwent anatomical lung resection, but there were 8 patients who underwent wedge resection. When choosing wedge resection cases, patients with peripheral and single nodules were preferred. On the other hand, we had 3 patients who underwent lung wedge biopsy due to interstitial lung disease. In these patients, we paid attention to criteria such as peripheral involvement, no signs of pleural adhesion in thorax $\mathrm{CT}$, and no respiratory distress.

In addition to pleural diseases, pulmonary peripheral nodules, or lung resections reported from experienced cen-

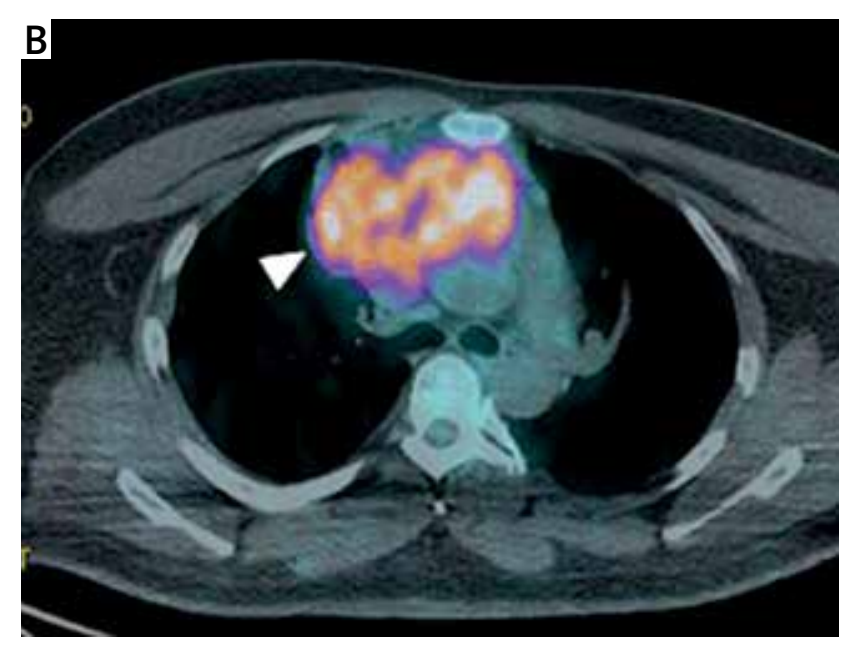

Figure 4. Thorax CT (A, asterisk) and PET-CT (B, arrowhead) images of anterior mediastinal mass. $\mathbf{C}$ - Intraoperative view of the anterior mediastinal mass (asterisk)

tres, it has been shown that mediastinal tumour surgery can be performed with this technique. Jiang et al. [15] reported that they performed VATS thymectomy safely in 36 patients under spontaneous breathing support. Following this, Liu et al. [16] also reported a non-intubated subxiphoid VATS thymectomy case. Thanks to these studies, it is thought that postoperative myasthenic crisis and postoperative prolonged tracheal intubation can be reduced in myasthenia gravis patients $[15,16]$. In our patient series, there were 4 patients who underwent mediastinal mass biopsy, and we did not see any complications in these patients.

The anaesthesia part of non-intubated VATS is also very important. It is known that preoperative anaesthesia preparation for single-lung ventilation in thoracic surgery is a detailed procedure that takes a long time. This extends the time spent by the patient in the operations room in total. Ambrogi et al. [17] showed in their study on 48 patients that the total time spent in the operating room in the nonintubated group was shorter than in the intubated group. The mean was 66 minutes in the non-intubated group, and 78 minutes in the intubated group, which was considered statistically significant [17]. In the meta-analysis of Chen et al., although there are similarities among the patients, it was reported that the time spent in the operations room 
was shortened, and side effects related to general anaesthesia were not observed [18].

One of the most important factors affecting patient comfort in postoperative follow-up is drain removal time. In our patients, VAS pain scores were measured as $2 \pm 0.6$, and the time to remove the drain was found to be 1.75 \pm 0.80 days - the low values in these patients shortened the healing process. Hsiao et al. [19] showed that the drainage times of 12 patients who underwent single-port non-intubated VATS due to parapneumonic empyema were significantly lower than in patients who were treated with tube thoracostomy. Drainage days, postoperative fever subsided days, postoperative hospital days, and the total length of stay were evaluated in these patients, and a significant difference was found in all of them [19]. Drain removal time provides early control of postoperative pain. Another feature of this study is that, like our first cases, surgery was successfully performed in patients with coronary artery disease and reduced left ventricular ejection fraction, high risk of general anaesthesia, and high comorbidity [19].

Video-assisted thoracoscopic surgery has some complications such as bleeding, prolonged air leak, and postoperative pain [20]. In our patient series, prolonged air leakage was observed in 1 patient, and arrhythmia was observed in 1 patient. Our complication rate was found to be $6 \%$, but because we are meticulous about patient selection we think that this rate may change with the increasing number of patients. General anaesthesia-related problems in VATS surgery were intubation-related airway trauma, increased risk of pneumonia, ventilator-associated lung injury, impaired cardiac performance, effects of neuromuscular blocking agents, and postoperative nausea and vomiting [21]. As a result of non-intubated VATS application with regional anaesthesia, only 1 patient suffered from nausea requiring medical treatment. We performed the surgical procedure very safely in 32 patients, and we did not have any patients who required intubation or returned to thoracotomy in the perioperative period. However, we think that conditions such as patients considered difficult to intubate, morbidly obese, those with intense pleural adhesions, and central and large tumours should be considered as contraindications for non-intubated VATS, especially until the surgical experience is increased.

When we look at the literature, we see that the recovery time and hospital stay are short in the patient series published [22]. We obtained results compatible with the literature in our patients. Our hospital stay was found to be $2.3 \pm 1.25$ days. Because our patient series included a small number of patients, our study had some limitations. However, we still see that non-intubated VATS is a reliable method in terms of patient comfort and rapid recovery.

\section{Conclusions}

The non-intubated VATS approach can be safely applied in procedures such as lung resections, pleural or mediastinal interventions, and pneumothorax surgery. Both teams must be experienced because it is a technique that is dependent on the surgeon and anaesthesia team. With this technique,
Table III. Performed surgical procedures

\begin{tabular}{lcc} 
Surgical procedures & $\begin{array}{c}\text { Number } \\
\text { of patients }\end{array}$ & $\%$ \\
\hline Pleural drainage and biopsy & 10 & 31.2 \\
\hline Wedge resection & 8 & 25 \\
\hline Bullectomy and pleural abrasion & 6 & 18.8 \\
\hline Empyema delocculation & 4 & 12.5 \\
\hline Mediastinal tumour biopsy & 4 & 12.5 \\
\hline
\end{tabular}

Table IV. Perioperative and postoperative information of our patients

\begin{tabular}{lc} 
Parameter & Values \\
$\begin{array}{l}\text { Anaesthetic induction } \\
\text { duration [minutes] }\end{array}$ & $21 \pm 3.6(15-30)$ \\
\hline
\end{tabular}

Aminutes]

\begin{tabular}{lll}
\hline Number of port incisions: & & \\
\hline Uniportal & 13 & 40.6 \\
\hline Biportal & 19 & 59.4 \\
\hline
\end{tabular}

\begin{tabular}{lcc}
\hline Operation time [minutes] & $28.4 \pm 9.56(18-50)$ & - \\
\hline Drain type: & & \\
\hline Hemovac drain & 16 & 50 \\
\hline $20 \mathrm{Fr}$ & 10 & 31.2 \\
\hline $28 \mathrm{Fr}$ & 6 & 18.8 \\
\hline Intraoperative blood loss [ml] & $16.4 \pm 0.64(5-50)$ & -
\end{tabular}

\begin{tabular}{lcl}
\hline Intraoperative blood loss [ml] & $16.4 \pm 0.64(5-50)$ & - \\
\hline Conversion to thoracotomy & 0 & - \\
\hline Conversion to intubation & 0 & - \\
\hline $\begin{array}{l}\text { VAS score (in postoperative } \\
\text { first } 24 \text { hours) }\end{array}$ & $2 \pm 0.6(1-3)$ & -
\end{tabular}

first 24 hours)

Side effect of anaesthesia:

\begin{tabular}{lcc}
\hline Vomiting & 1 & 3 \\
\hline Complications $(n=2,6 \%):$ & & \\
\hline Air leak & 1 & 3 \\
\hline Cardiac arrythmia & 1 & - \\
\hline Drain removal time [days] & $1.75 \pm 0.80(1-4)$ & - \\
\hline Hospital stay [days] & $2.3 \pm 1.25(1-5)$ & \\
\hline
\end{tabular}

the absence of intubation and mechanical ventilation provides a faster return to normal respiratory physiology. In this way, the cost of hospital recovery will decrease by reducing the time of patient recovery and hospital stay. The reliability and effectiveness of non-intubated VATS should be evaluated with broader randomized studies.

\section{Disclosure}

The authors report no conflict of interest.

\section{References}

1. Ocakcioglu I. Uniportal thoracoscopic treatment in bronchiectasis patients: preliminary experience. Videosurgery Miniinv 2019; 14: 304-310.

2. Galvez C, Navarro-Martinez J, Bolufer S, Lirio F, Sesma J, Corcoles JM. Nonintubated uniportal VATS pulmonary anatomical resections. J Vis Surg 2017; 3: 120 
3. Ahn S, Moon Y, AlGhamdi ZM, Sung SW. Nonintubated uniportal videoassisted thoracoscopic surgery: a single-center experience. Korean J Thorac Cardiovasc Surg 2018; 51: 344-349.

4. Liu YJ, Hung MH, Hsu HH, Chen JS, Cheng YJ. Effects on respiration of nonintubated anesthesia in thoracoscopic surgery under spontaneous ventilation. Ann Transl Med 2015; 3: 107.

5. Jung J, Kim DH, Son J, Lee SK, Son BS. Comparative study between local anesthesia and general anesthesia in the treatment of primary spontaneous pneumothorax. Ann Transl Med 2019; 7: 553.

6. Kocatürk C, Kutluk AC, Usluer O, Onat S, Çınar HU, Yanık F, Cesur E, Ülkü R, Karamustafaoğlu A, Çelik B, Demirhan R, Kalafat CE, Özpolat B. Comparison of awake and intubated video-assisted thoracoscopic surgery in the diagnosis of pleural diseases: a prospective multicenter randomized trial. Turk Gogus Kalp Damar Cerrahisi Derg 2019; 27: 550-556.

7. AlGhamdi ZM, Lynhiavu L, Moon YK, Moon MH, Ahn S, Kim Y, Sung SW. Comparison of non-intubated versus intubated video-assisted thoracoscopic lobectomy for lung cancer. J Thorac Dis 2018; 10: 4236-4243.

8. Navarro-Martínez J, Gálvez C, Rivera-Cogollos MJ, Galiana-Ivars M, Bolufer S, Martínez-Adsuar F. Intraoperative crisis resource management during a nonintubated video-assisted thoracoscopic surgery. Ann Transl Med 2015; 3: 111.

9. Liu J, Cui F, Li S, Chen H, Shao W, Liang L, Yin W, Lin Y, He J. Nonintubated video-assisted thoracoscopic surgery under epidural anesthesia compared with conventional anesthetic option: a randomized control study. Surg Innov 2015; 22: 123-130.

10. Chow SC, Ng CS. Recent developments in video-assisted thoracoscopic surgery for pulmonary nodule management. J Thorac Dis 2016; 8: 509-516.

11. Solli P, Brandolini J, Bertolaccini L. Tubeless thoracic surgery: ready for prime time? J Thorac Dis 2019; 11: 652-656.

12. Pompeo E, Mineo D, Rogliani P, Sabato AF, Mineo TC. Feasibility and results of awake thoracoscopic resection of solitary pulmonary nodules. Ann Thorac Surg 2004; 78: 1761-1768.
13. Gonzalez-Rivas D, Fernandez R, de la Torre M, Rodriguez JL, Fontan L, Molina F. Single-port thoracoscopic lobectomy in a nonintubated patient: the least invasive procedure for major lung resection? Interact Cardiovasc Thorac Surg 2014; 19: 552-555.

14. Shao W, Phan K, Guo X, Liu J, Dong Q, He J. Non-intubated complete thoracoscopic bronchial sleeve resection for central lung cancer. J Thorac Dis 2014; 6: $1485-1488$.

15. Jiang L, Depypere L, Rocco G, Jin-Shing Chen JS, Liu J, Shao W, Yang H, He JX; AME Thoracic Surgery Collaborative Group. Spontaneous ventilation thoracoscopic thymectomy without muscle relaxant for myasthenia gravis: comparison with "standard" thoracoscopic thymectomy. J Thorac Cardiovasc Surg 2018; 155: 1882-1889.

16. Liu Z, Yang R, Sun Y. Non-intubated subxiphoid uniportal video-assisted thoracoscopic thymectomy. Interact Cardiovasc Thorac Surg 2019; 29: 742-745.

17. Ambrogi V, Sellitri F, Perroni G, Schillaci O, Mineo TC. Uniportal video-assisted thoracic surgery colorectal lung metastasectomy in non-intubated anesthesia. J Thorac Dis 2017; 9: 254-261.

18. Chen W, Zhang C, Wang G, Li Z, Wang H, Liu H. The feasibility and safety of thoracoscopic surgery under epidural and/or local anesthesia for spontaneous pneumothorax: a meta-analysis. Videosurgery Miniinv 2017; 12: 216-224.

19. Hsiao $\mathrm{CH}$, Chen KC, Chen JS. Modified single-port non-intubated video-assisted thoracoscopic decortication in high-risk parapneumonic empyema patients. Surg Endosc 2017; 31: 1719-1727.

20. Łochowski MP, Kozak J. Video-assisted thoracic surgery complications. Videosurgery Miniinv 2014; 9: 495-500.

21. Kao MC, Lan CH, Huang CJ. Anesthesia for awake video-assisted thoracic surgery. Acta Anaesthesiol Taiwan 2012; 50: 126-130.

22. Mineo TC, Sellitri F, Tacconi F, Ambrogi V. Quality of life and outcomes after nonintubated versus intubated video-thoracoscopic pleurodesis for malignant pleural effusion: comparison by a case-matched study. J Palliat Med 2014; 17: 761-768. 